\title{
Desulfurization of Saudi Arabian crudes by oxidation-extraction method
}

\author{
Raja L. AL Otaibi ${ }^{1}$ Dong Liu ${ }^{2}$ Xulian $\mathrm{Hou}^{2} \cdot$ Linhua Song ${ }^{3}$ Qingyin $\mathrm{Li}^{3}$. \\ Mengfei $\mathrm{Li}^{4} \cdot$ Hamid O. Almigrin ${ }^{2} \cdot$ Zifeng Yan $^{2}$
}

Received: 8 March 2015/Accepted: 19 May 2015/Published online: 6 June 2015

(c) The Author(s) 2015. This article is published with open access at Springerlink.com

\begin{abstract}
The oxidation-extraction desulfurization of Saudi Arabian crudes was conducted with hydrogen peroxide-acetic acid oxidation system. The selection of extractant, the optimization of oxidation-extraction conditions, and the exploration of desulfurization mechanism were studied. As DMF was used as the extractant, the optimal desulfurization rate of $35.11 \%$ and oil recovery of $95 \%$ were obtained at $70{ }^{\circ} \mathrm{C}$ with the molar ratio of peracetic acid to sulfur of $8: 1$, the molar ratio of acetic acid to hydrogen peroxide of $2: 1$ and the volume ratio of extractant to oil of 1:1. The desulfurization effect of different fractions in the treated Saudi Arabian crudes was found to obey the following order: gasoline-diesel fraction $>$ VGO fraction $>$ VR fraction, due to different types and structures of sulfur compounds. The oil quality was less affected and most sulfides were mainly extracted via DMF.
\end{abstract}

Keywords Saudi Arabian crudes - Oxidation-extraction · Desulfurization · Fractions

Dong Liu

ldongupc@vip.sina.com

$\triangle$ Xulian Hou

zhenzhen_0420@126.com

1 Petrochemical Research Institute, King Abdulaziz City for Science and Technology, PO Box 6086, Riyadh 11442, Kingdom of Saudi Arabia

2 State Key Laboratory of Heavy Oil Processing, China University of Petroleum, Qingdao 266580, China

3 College of Science, China University of Petroleum, Qingdao 266580, China

4 College of Chemical Engineering, Qingdao University of Science and Technology, Qingdao 266000, China

\section{Introduction}

With rapid development of economy and technology and increasing demand for crude oil exploitation, the content of sulfur-contenting compounds in the crude oil is ever increasing, leading to poor oil quality. The dissolved sulfides, such as hydrogen sulfide, sulfoether, mercaptan, disulfide, and thiophene, may corrode the equipment in the exploitation, transportation and refining process [1, 2], directly affecting the safe production and even polluting the environment. Therefore, the technology of crude oil desulfurization has attracted more and more interests, and the extensive researches mainly on the non-hydrogenation desulfurization (NHDS) are received [3-5]. The ultrasonic oxidation and bacteria desulfurization methods that remove some sulfides of the heavy crude oil are developed by Sulphco U.S Company [6] and Iran Sharif University of Technology [7], respectively. Additionally, the desulfurizer GX 201D in Changqing desulfurization process could be added into crude oil directly, but it was nonrenewable.

At present, the industrial desulfurization processing technologies of crude oil are still immature. Especially, the desulfurization effect on organic sulfur compounds is insignificant. In view of advantages of mild reaction conditions, high selectivity and low cost [8-10], the deep oxidation desulfurization process has received more concern recently which can remove the refractory sulfur compounds significantly. The oxidants commonly used include $\mathrm{NO}_{2} / \mathrm{HNO}_{3}, \mathrm{O}_{3}$, peroxyacid and tertbutyl hypochlorite [11-13]. $\mathrm{H}_{2} \mathrm{O}_{2}$ (as oxidant) with organic acid (as oxidation accelerator) among them is widely used in light oil desulfurization process but hardly in crude oil [14]. Moreover, there are few researches systematically on the oxidation desulfurization mechanism. 
In this paper, the $30 \mathrm{wt} \% \mathrm{H}_{2} \mathrm{O}_{2}$-acetic acid oxidation system was utilized to remove the sulfides from the Saudi Arabian crudes. The optimization of oxidation and extraction conditions was studied, including peracetic acid dosage, $\mathrm{HAc} / \mathrm{H}_{2} \mathrm{O}_{2}$ ratio, temperature, reaction time, selection of extractant. The desulfurization effect of different fractions in crude oil was also investigated. Additionally, the oxidation extraction mechanism was proposed.

\section{Experimental}

\section{Materials}

A sample of treated crude oil (Sulfur content, $2.5 \mathrm{wt} \%$ ) was obtained from Saudi Arabia; Hydrogen peroxide $\left(\mathrm{H}_{2} \mathrm{O}_{2}, 30\right.$ wt $\%$ ), acetic acid (HAc), $N, N$-dimethylformamide(DMF), dimethylsulfoxide(DMSO), ethanol, ethylene glycol and furfural were purchased commercially.

\section{Oxidation and extraction of crude oil}

The oxidation of Saudi Arabian crudes was conducted in a glass flask with an electric stirrer. An excess amount of 30 wt $\% \mathrm{H}_{2} \mathrm{O}_{2}$ and acetic acid was used to oxidize the sulfur compounds thoroughly. First, $\mathrm{H}_{2} \mathrm{O}_{2}$ and $\mathrm{HAC}$ were mixed at a certain ratio to prepare the peracetic acid, which was then put into the crude material. Subsequently, the mixture was stirred at the desired temperature for a certain time.

The extraction of Saudi Arabian crudes was conducted in a three-neck glass flask with an electric stirrer. The extractant was added to the oxidation reaction system. The extraction reaction was carried out at $60{ }^{\circ} \mathrm{C}$ for $20 \mathrm{~min}$. Thereafter, the treated crude oil was obtained by centrifuging after the mixture was cooled to room temperature. Finally, oil and solvent were separated using a separatory funnel.

\section{Analysis}

The sulfur content (wt\%) of the crude oil was measured by tubular furnace (Shandong Xianke Instruments Co., Ltd. $\left.\mathrm{SX}_{2}-5-1\right)$. The desulfurization rate can be calculated by the following equations:

$\eta=\frac{\omega 1-\omega 2}{\omega 1} \times 100 \%$

where

$\eta$ : desulfurization rate, $\%$;

$\omega 1$ : sulfur compounds content of crude oil, \%;

$\omega 2$ : sulfur compounds content of treated crude oil, $\%$.

The treated crude oil was distillated to obtain gasolinediesel fraction, VGO fraction $\left(350-450{ }^{\circ} \mathrm{C}\right)$ and VR fraction, respectively. The gasoline-diesel fraction was characterized by GC-PFPD (USA, GC3800). Besides, VGO fraction was analyzed by GC-MS (Agilent Technologies Co., Ltd., GC6890) and VR fraction was separated into saturates, aromatics, resins and asphaltenes to study the reaction mechanism. As to the GC-PFPD analysis, a HP-5HS $(30 \mathrm{~m} \times 0.32 \mathrm{~m} \times 0.25 \mu \mathrm{m})$ column was initially maintained at $80^{\circ} \mathrm{C}$ for $2 \mathrm{~min}$, then the temperature was ramped to $280{ }^{\circ} \mathrm{C}$ at $3{ }^{\circ} \mathrm{C} / \mathrm{min}$ and maintained for $10 \mathrm{~min}$. The temperature of sample injector was set to $320{ }^{\circ} \mathrm{C}$. The carrier gas was high-purity nitrogen, and the flow rate was $1.0 \mathrm{~mL} / \mathrm{min}$. Injection volume was $1 \mu \mathrm{L}$.

In addition, crude oil before/after desulfurization and oil in the extractant were analyzed by infrared spectrometer (IR 1730) to investigate the effect of the oxidation-extraction system on the oil quality and distribution of the sulfur compounds.

\section{Results and discussion}

\section{Optimization of oxidation conditions}

The different oxidation conditions were conducted to study the oxidative desulfurization effect. In this section, the extraction experiment was carried out at $60{ }^{\circ} \mathrm{C}$ for $20 \mathrm{~min}$ with DMF as extractant, and the extractant to oil volume ratio $(\mathrm{E} / \mathrm{O})$ was one. The results are shown in Fig. 1.

$\mathrm{H}_{2} \mathrm{O}_{2}$ /organic acid oxidation desulfurization method has been widely investigated and it is a very mature method which can satisfy the purpose of green chemistry in light oil desulfurization process. Otsuki et al. [15] have reported that the sulfur content of oxidized vacuum gas oil was reduced to $0.01 \mathrm{wt} \%$ and most of benzothiophene compounds were removed by $\mathrm{H}_{2} \mathrm{O}_{2}$ /formic acid oxidation-extraction system.

Figure 1a shows the effect of different organic acids (as oxidation accelerator). The acetic acid was found to have better oxidation-desulfurization effect than formic acid. $\mathrm{H}_{2} \mathrm{O}_{2}$ /formic acid system was unable to desulfur effectively due to inherent strong acidity of formic acid. The selectivity in this reaction is much lower under these severe conditions, resulting in sulfides being oxidized incompletely. Additionally, some polar compounds such as the unsaturated hydrocarbons in the crude oil can be also oxidized and extracted simultaneously. To be concluded, on the one hand, the oxidation selectivity for the sulfurcontaining compounds and utilization efficiency for $\mathrm{H}_{2} \mathrm{O}_{2} /$ organic acid system would be reduced by the strong acidic reaction condition. Thus, a large quantity of oxidant is required and the operation cost is increased. On the other hand, the quality of the crude oil would be changed badly. Clearly, the acidity of acetic acid is weaker than that of 

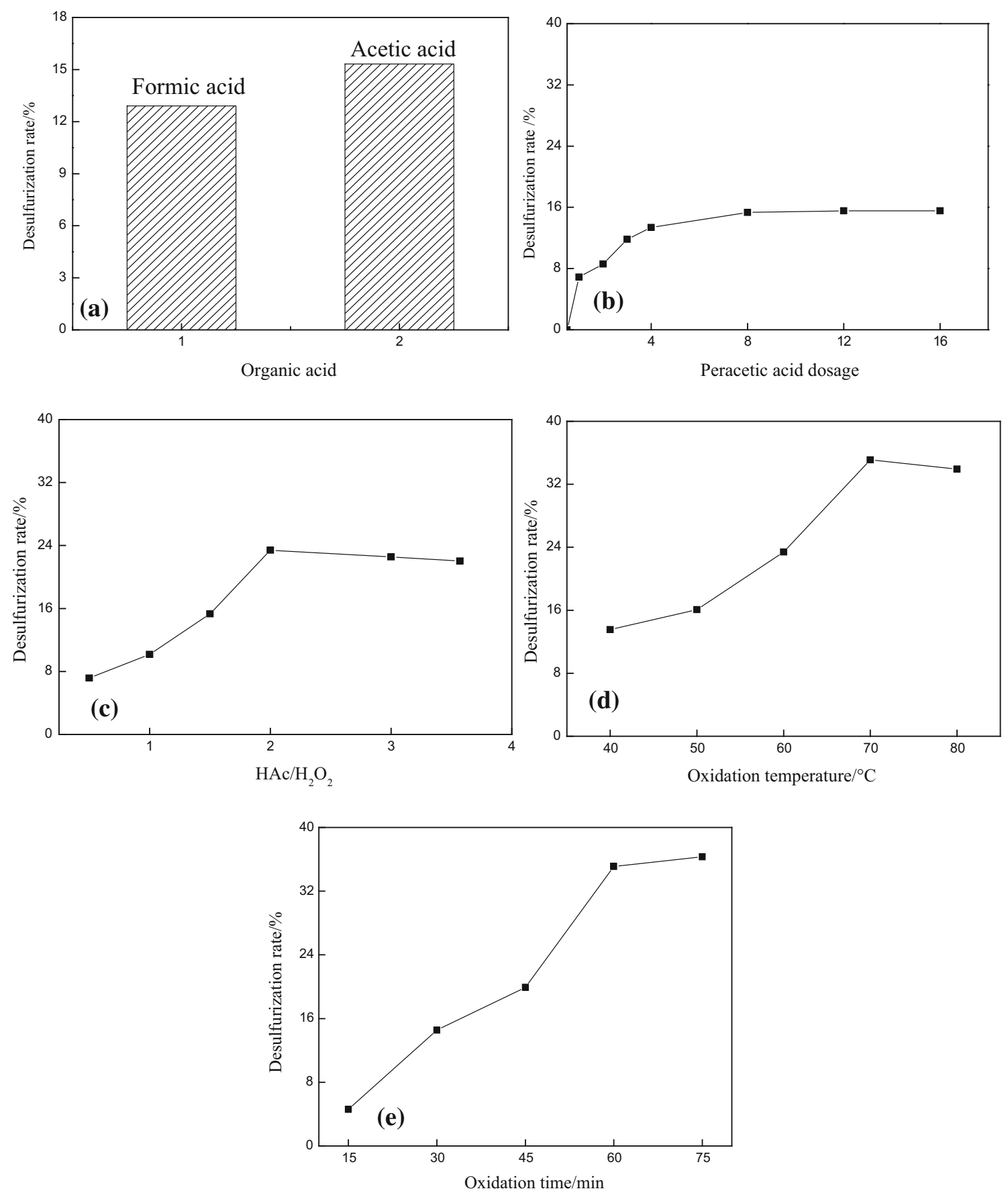

Fig. 1 Effect of oxidation conditions on the desulfurization rate. (Peracetic acid dosage is the molar ratio of peracetic acid to sulfur in the oil)

formic acid, and then proper oxidation desulfurization of crude oil could be acquired through $\mathrm{H}_{2} \mathrm{O}_{2}$ /acetic acid oxidation system. Especially, the resulted oily quality was less affected during the process. The influence of peracetic acid dosage ranging from 0 to 16 was investigated, as the acetic acid/hydroperoxide molar ratio, oxidation temperature and oxidation time were $1.5,60{ }^{\circ} \mathrm{C}$ and $60 \mathrm{~min}$. As shown in Fig. $1 \mathrm{~b}$, the desulfurization rate increases initially with the increase of peracetic acid dosage, and then it levels off at $16 \%$, suggesting that the optimized molar ratio of peracetic acid to sulfur is $8: 1$.

Effect of $\mathrm{HAc} / \mathrm{H}_{2} \mathrm{O}_{2}$ ratio on sulfur removal is depicted in Fig. 1c. Molar ratio of peracetic acid to sulfur is 8:1, oxidation temperature is $60{ }^{\circ} \mathrm{C}$ and oxidation time is $60 \mathrm{~min}$. Desulfurization rate presents an uptrend when $\mathrm{HAc} / \mathrm{H}_{2} \mathrm{O}_{2}$ ratio is smaller than two and it decreases 
slightly with $\mathrm{HAc} / \mathrm{H}_{2} \mathrm{O}_{2}$ ratio further increased. It was explained that HAc could catalyze reaction as an oxidation accelerator; however, excessive acidity may impair the stability of DMF and weaken extraction effect, leading to reducing the desulfurization rate slightly. Therefore, HAc/ $\mathrm{H}_{2} \mathrm{O}_{2}$ ratio of two is chosen.

As illustrated in Fig. 1d, the reaction proceeds completely with the oxidation temperature increased. In particular, the desulfurization rate decreases obviously due to decomposition of $\mathrm{H}_{2} \mathrm{O}_{2}$ and peracetic acid with temperature exceeded $70{ }^{\circ} \mathrm{C}$. Additionally, the unsaturated hydrocarbons and the nitrogen/oxygen-containing compounds are also oxidized, which could destroy the quality of oil and weaken the oxidation selectivity. Therefore, the optimal oxidation temperature is $70{ }^{\circ} \mathrm{C}$.

Figure 1e illustrates that the desulfurization rate elevated obviously with the increasing oxidation time. The oxidation reaction may be completed in $60 \mathrm{~min}$, which was the optimized reaction time.

In conclusion, the optimal oxidation conditions are as follows: $\mathrm{H}_{2} \mathrm{O}_{2}$ /acetic acid system is chosen, the molar ratio of peracetic acid to sulfur is $8: 1 ; \mathrm{HAc} / \mathrm{H}_{2} \mathrm{O}_{2}$ molar ratio is 2; the oxidation temperature is $70{ }^{\circ} \mathrm{C}$; the oxidation time is $60 \mathrm{~min}$.

\section{Optimization of extraction conditions}

Thiophenes can be oxidized to sulfones by peracetic acid [16]. In view of atomic structure, sulfur atoms have five more $3 \mathrm{~d}$ orbits than that of carbon atoms, so they are able to be oxidized easily. Compared with organic sulfur-containing compounds, the generated organic oxides have higher dipole moments, resulting in the increased solubility in DMF, ethanol, DMSO and some other polar solvents. The extraction experiment was carried out under the optimal oxidation condition.

As seen in Table 1, the desulfurization rate of DMF is much higher than that of other solvents at extraction temperature and time of $60{ }^{\circ} \mathrm{C}$ and $20 \mathrm{~min}$. Moreover, it could be recovered from atmospheric distillation, thus DMF is selected as suitable extractant.

Figure 2 shows the influence of the DMF to oil volume ratio $(\mathrm{E} / \mathrm{O})$ on the extraction process. The extracted oxide reached to the maximum extent with $E / O$ of $1-1.5$. Some polar components could also be extracted as $\mathrm{E} / \mathrm{O}$ ratio was

Table 1 Effect of extractant on the desulfurization rate

\begin{tabular}{llllll}
\hline Extractant & DMF & DMSO & Ethanol & $\begin{array}{l}\text { Ethylene } \\
\text { glycol }\end{array}$ & Furfural \\
\hline $\begin{array}{l}\text { Desulfurization } \\
\text { rate/\% }\end{array}$ & 35.11 & 20.31 & 6.92 & 11.19 & - \\
\hline
\end{tabular}

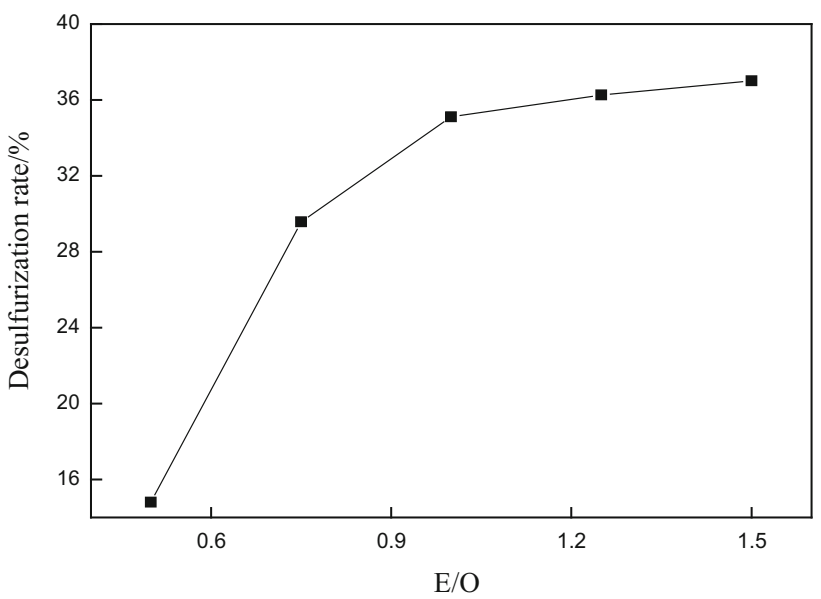

Fig. 2 Effect of the extractant to oil volume ratio on the desulfurization rate

higher than 1.5, which would reduce the yield of crude oil accordingly. Hence, the chosen E/O ratio was 1, in which the obtained desulfurization rate was up to 35.11 and $95 \%$ of oil could be recovered.

\section{Mechanism study of the desulfurization effect}

\section{The yield and desulfurization effect of different fractions}

The qualitative analysis on the various sulfides was limited due to the complex composition in the crude oil. Hence, the Saudi Arabian crudes treated from the optimal desulfurization conditions were distilled into three fractions, to further investigate the desulfurization effect on different fractions.

Table 2 shows that different fractions yield remain almost unchanged after oxidative desulfurization, indicating the occurrence of some side reactions during the desulfurization process. In other words, the experimental system has a little influence on the crude oil composition, which makes the process promising for future applications.

The desulfurization rate obeys the following order: gasoline-diesel $>$ VGO $>$ VR. On the one hand, the heavy fraction contains more complicated sulfur compounds with stable structure, suggesting that desulfurization process was in trouble. On the other hand, the components with more strong polarity existed in the heavy fraction could be extracted readily via DMF, which would weaken the sulfur removal effect.

\section{GC analysis of gasoline-diesel fraction}

Mercaptan belongs to weak acid, and thus can be oxidized easily to disulfide. The alkyl sulfide is a neutral liquid substance, and the disulfide has a poor stability. Both are 
Table 2 The fractions yield and desulfurization rate

\begin{tabular}{llll}
\hline Fractions & $\begin{array}{l}\text { Gasoline- } \\
\text { diesel }\end{array}$ & $\operatorname{VGO}\left(350-450{ }^{\circ} \mathrm{C}\right)$ & $\mathrm{VR}$ \\
\hline $\begin{array}{l}\text { Yield before } \\
\text { desulfurization/\% }\end{array}$ & 33.47 & 19.44 & 47.09 \\
$\begin{array}{l}\text { Yield after } \\
\text { desulfurization/\% }\end{array}$ & 32.28 & 20.17 & 47.55 \\
$\begin{array}{l}\text { Desulfurization rate/\% } \\
\text { Pes. }\end{array}$ & 59.25 & 37.58 & 13.25 \\
\hline
\end{tabular}

Table 3 Changes of sulfur content in gasoline-diesel fraction

\begin{tabular}{|c|c|c|c|}
\hline \multirow{2}{*}{$\begin{array}{l}\text { Types of } \\
\text { sulfide }\end{array}$} & \multicolumn{2}{|c|}{ Sulfur content $/ \mu \mathrm{g} \mathrm{g}^{-1}$} & \multirow{2}{*}{$\begin{array}{l}\text { Desulfurization } \\
\text { rate/\% }\end{array}$} \\
\hline & $\begin{array}{l}\text { Before } \\
\text { desulfurization }\end{array}$ & $\begin{array}{l}\text { After } \\
\text { desulfurization }\end{array}$ & \\
\hline $\begin{array}{l}\text { Mercaptan } \\
\text { sulfur }\end{array}$ & 196.86 & 20.24 & 89.72 \\
\hline Alkyl sulfide & 66.68 & 9.20 & 86.20 \\
\hline Disulfide & 737.32 & 6.04 & 99.18 \\
\hline $\begin{array}{l}\text { Alkyl } \\
\text { thiophene }\end{array}$ & 1754.88 & 67.00 & 96.18 \\
\hline BT & 2351.62 & 1341.58 & 42.95 \\
\hline DBT & 2659.64 & 1718.72 & 35.38 \\
\hline Others & 148.16 & 62.54 & 57.79 \\
\hline Total & 7915.16 & 3225.32 & 59.25 \\
\hline
\end{tabular}

prone to be oxidized to sulfoxide or sulfonic acid [17], and then removed by extractant. As shown in Table 3, alkylthiophene $(96.18 \%)$, benzothiophene $(42.95 \%)$ and dibenzothiophene $(35.38 \%)$ in gasoline-diesel fraction have been removed after oxidative-extractive reaction.
The formula for oxidation desulfurization mechanism is as follows:

$\mathrm{H}_{2} \mathrm{O}_{2}+\mathrm{CH}_{3} \mathrm{COOH} \longrightarrow \mathrm{H}_{2} \mathrm{O}+\mathrm{CH}_{3} \mathrm{COOOH}$ (quickly)<smiles>CC(=O)OCCCCOC(C)=O</smiles>

As the organic sulfur compounds are oxidized to the corresponding sulfoxide and/or sulfone by peracetic acid, the efficiency of desulfurization can be significantly increased using DMF extraction. Previous researches [15] suggest that the density of electron cloud and space steric hindrance play a critical role in the oxidative desulfurization. The oxidation reaction rate constant $k$ increases with the electron cloud density of sulfur atoms. Hence, the reactivity of sulfur compounds is enhanced with the electron density increased for sulfur atom. The effect of oxidative desulfurization should be as follows: dibenzothiophene $>$ benzothiophene $>$ thiophene. However, the experimental results are contrary to the above conclusions. It is speculated that the space steric hindrance may be the dominant factor in the reaction. It should be noted that $59.25 \%$ sulfurs have been removed thoroughly by DMF extraction, indicating that oxidative products in the gasoline-diesel fraction could be extracted effectively to achieve the deep desulfurization goal.

\section{GC-MS analysis of the VGO fraction}

The obtained VGO $\left(350-450{ }^{\circ} \mathrm{C}\right)$ fraction was characterized by GC-MS. The results are listed in Table 4. Some specific sulfides including thioether, benzothiophene,
Table 4 Sulfur compounds' structures and desulfurization rate in the VGO fraction

\begin{tabular}{|c|c|c|c|}
\hline NO. & Formulas & Structures & $\begin{array}{c}\text { Desulfurization } \\
\text { rate } \% \%\end{array}$ \\
\hline 1 & $\mathrm{C}_{16} \mathrm{H}_{10} \mathrm{~S}$ & & 59.17 \\
\hline 2 & $\mathrm{C}_{15} \mathrm{H}_{14} \mathrm{~S}$ & & 18.97 \\
\hline 3 & $\mathrm{C}_{16} \mathrm{H}_{10} \mathrm{~S}$ & & 12.63 \\
\hline 4 & $\mathrm{C}_{17} \mathrm{H}_{12} \mathrm{~S}$ & & 10.38 \\
\hline 5 & $\mathrm{C}_{18} \mathrm{H}_{14} \mathrm{~S}$ & & 9.75 \\
\hline 6 & $\mathrm{C}_{12} \mathrm{H}_{14} \mathrm{~N}_{2} \mathrm{~S}$ & & 6.53 \\
\hline
\end{tabular}


benzonaphthothiophene and benzisothiazole could be identified. After oxidation, these sulfur compounds were reacted to sulfones, and then removed partly after extraction. Especially the di-n-octylsulfide removal rate is the highest, followed by trimethyldibenzothiophene removal rate, while the other sulfide removal rates are relatively low. It is speculated that this is mainly due to the effect of space steric hindrance and inhibition of $N$ atoms.

The sulfur compounds in the VGO fraction existed mainly in forms of thiophene, benzothiophene, dibenzothiophene compounds and derivatives. Due to the weak polarity in the carbon-carbon bones and carbon-sulfur bones, both organic sulfur-containing species and the corresponding hydrocarbons had the similar polarity. Hence, the sulfur compounds in the crude oil were unable to be removed via polar solvents.

From the molecular perspective, the $d$ orbital electrons were presented in the sulfur atom, so the sulfides were prone to be oxidized selectively to the sulfoxide or sulfone with stronger polarity by peracetic acid. As the oxygen atoms were bonded to the sulfur atoms, dipole moment of the sulfur compounds increased accordingly, and thus their dissolving capacity in the polar solvents (DMF, DMSO, etc.,) was enhanced significantly.

The extraction process was conducted through hydrogen bond interactions between extractant and oxidized compounds, and the selectivity of extractant to the sulfides was vital in the desulfurization process. The desulfurization efficiency was affected greatly by the physicochemical properties of utilized organic solvent, especially polarity. It was shown that the solvent with high polarity may extract the oxidized sulfur compounds (sulfones) effectively, and DMF was considered as the most suitable extractant among these solvents used.

In this study, it was demonstrated that thiophene, benzothiophene, dibenzothiophene compounds and derivatives were oxidized via $\mathrm{CH}_{3} \mathrm{COOOH}$ and extracted through DMF.

\section{Four components analysis of the VR fraction}

Four components analysis of VR is conducted to investigate the influence of the oxidation-extraction system on the VR fraction compositions. The results (Fig. 3) indicate that the relative yields of saturates and aromatics declined slightly, on the contrary, the yields of resins and asphaltenes increased after desulfurization. Thus, it was preliminarily inferred that some saturates and aromatics were condensed into resins and asphaltenes.

The major sulfides are thioether and thiophene in resins and asphaltenes, such as alkyl thiophene, dibenzothiophene and five- or six-membered ring thioether. In terms of the aromatic heterocyclic compound, thiophene was unable to

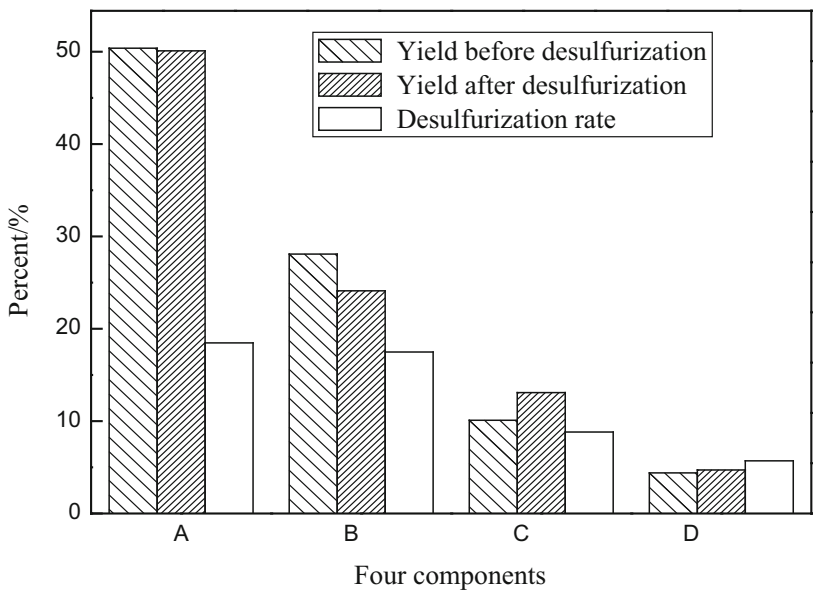

Fig. 3 Four components analysis of the VR fraction, $A$ saturates, $B$ aromatics, $C$ resins, $D$ asphaltenes

be removed without efforts due to the stable structure and space steric effect. Desulfurization rate decreases in the following order: saturates $>$ aromatics $>$ resin $>$ asphaltenes. It can be explained that the polarity and condensation degree in the four components increased accordingly. The solubility of sulfides and their corresponding oxidation products-sulfones in the oil were enhanced with the strong polarities, leading to difficult removal.

\section{$I R$ analysis of crude oil and the oil in the extractant}

IR spectrums of the crude oil before and after desulfurization are shown in Fig. 4a, b. The results demonstrated that the oily quality hardly changed, indicating the experimental method is feasible.

Compared with raw material (Fig. 4a), oil in the extractant presents two strong absorption peaks at 1300 and $1160 \mathrm{~cm}^{-1}$ (Fig. 4c) (DMF and aqueous phase have been removed by distillation), which illustrated that the sulfides have been oxidized to the corresponding sulfones $\left(-\mathrm{SO}_{2}-\right)$. Furthermore, the characteristic adsorption peaks of $\mathrm{S}=\mathrm{O}$ bond (sulfoxide) and $-\mathrm{SO}_{3} \mathrm{H}$ (sulfonic acid) located at 1030 and $1160 \mathrm{~cm}^{-1}$ were obscure. They are probably covered by absorption peaks of $-\mathrm{SO}_{2}$-(sulfones) [18]. Besides, $1740 \mathrm{~cm}^{-1}$ is attributed to the presence of DMF, mainly caused by the remaining DMF after the distillation; $3400 \mathrm{~cm}^{-1}$ represented the absorption peak of vibration hydroxyl group, which may belong to residual moisture or alcohol generated during the oxidation process.

Finally, the sulfur content of the oil in the extractant is determined to be $10.8 \%$ approximately. Obviously, sulfide enrichment can be achieved by extracting the oxidation products from the oxidized oil. 

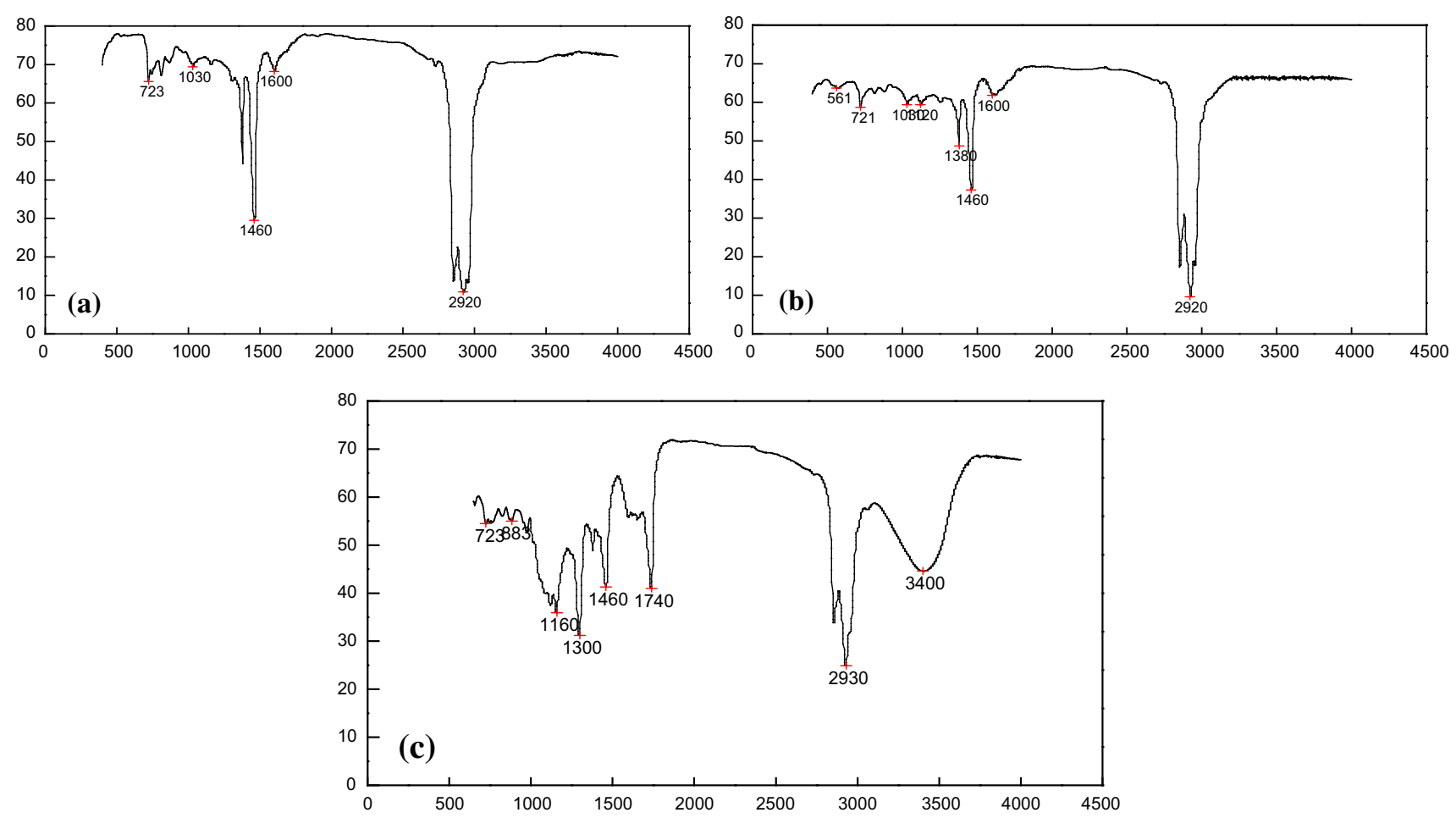

Fig. 4 IR analysis of crude oil and extracted oil. a Crude oil before desulfurization, $\mathbf{b}$ crude oil after desulfurization, $\mathbf{c}$ oil in the extractant

\section{Conclusions}

The oil quality changes a little and most of the sulfides are mainly extracted by DMF after desulfurization. The highest desulfurization rate is obtained at the oxidation temperature of $70{ }^{\circ} \mathrm{C}$ for 60 min with a $\mathrm{HAc}$ to $\mathrm{H}_{2} \mathrm{O}_{2}$ molar ratio of $2: 1$ and a peracetic acid to sulfur molar ratio of $8: 1$. DMF was confirmed to be the best extractant. The optimal extraction condition was considered to be carried out at $60{ }^{\circ} \mathrm{C}$ for 20 min with the extractant to oil volume ratio of $1: 1$. The desulfurization rate of Saudi Arabian crudes could reach as high as $35.11 \%$ and the oil recovery is about $95 \%$.

The desulfurization effect of different fractions, obtained from the treated Saudi Arabian crudes, is found to obey the following order: gasoline-diesel fraction $>$ VGO fraction $>$ VR fraction.

Acknowledgments This work was supported by the Fundamental Research Funds for the Central Universities(15CX05009A).

Open Access This article is distributed under the terms of the Creative Commons Attribution 4.0 International License (http:// creativecommons.org/licenses/by/4.0/), which permits unrestricted use, distribution, and reproduction in any medium, provided you give appropriate credit to the original author(s) and the source, provide a link to the Creative Commons license, and indicate if changes were made.

\section{References}

1. Qingtang Y (2008) Progress and outlook on technologies for processing inferior crude oil in China. China Petroleum Proc Petrochem Technol 1:1-7

2. Shafi R, Hutchings GJ (2000) Hydrodesulfurization of hindered dibenzothiophenes: an overview. Catal Today 59:423-442

3. Jianhua Q, Yuenan Z, Lin L et al (2009) Study on kinetics for desulfurization of model diesel. China Petroleum Proc Petrochem Technol 2:43-47

4. Yarong X, Shen Benxian X, Xinliang X et al (2010) FCC gasoline desulfurization through oxidation and extraction. Chem Ind Eng Prog 29(6):1051-1055 (in Chinese)

5. Dehkordi AM, Kiaei Z, Sobati MA (2009) Oxidative desulfurization of simulated light fuel oil and untreated kerosene. Fuel Process Technol 90(3):435-445

6. Agarwal P, Sharma DK (2009) Comparative studies on the biodesulfurization of crude oil with other desulfurization techniques and deep desulfurization through integrated processes. Energy Fuel 24(1):518-524

7. Bozhang Q (2008) Heavy crude oil desulfurization process by bacteria in Iran. Adv Fine Petrochem 10:19

8. Kumar S, Srivastava VC, Badoni RP (2012) Oxidative desulfurization by chromium promoted sulfated zirconia. Fuel Process Technol 93(1):18-25

9. Lin L, Hong L, MengFanfei L et al (2011) Optimization study on oxidative desulfurization of crude oil under electric field. China Petroleum Proc Petrochem Technol 13(3):59-63

10. Jianhua G, Yuming Z, Yong Y et al (2011) Catalytic oxidative desulfurization of gasoline using ionic liquid emulsion system. Ind Eng Chem Res 50(24):13686-13692 
11. Wenshuai Z, Guopeng Z, Huaming L et al (2011) Oxidative desulfurization of fuel catalyzed by metal-based surfactant-type ionic liquids. J Mol Catal A Chem 347(1):8-14

12. Hua S, Guozhong L, Zhengguang L (2010) Deep desulphurization of gasoline by catalytic oxidation using quaternary ammonium phosphotungstate as catalyst. J Fuel Chem Technol 38(4):439-444

13. Dehkordi AM, Kiaei Z, Sobati MA (2009) Oxidative desulfurization of simulated light fuel oil and untreated kerosene. Fuel Process Technol 90(3):435-445

14. Haixia L, Lingmei X, Jie M et al (2011) Comparative Study on oxidative desulfurization of FCC gasoline by $\mathrm{Ce}^{4+}$ compound and $\mathrm{H}_{2} \mathrm{O}_{2}$. China Petroleum Proc Petrochem Technol 13(4):23-28
15. Otsuki S, Nonaka T, Takashima N et al (2000) Oxidative desulfurization of light gas oil and vacuum gas oil by oxidation and solvent extraction. Energy Fuels 14(6):1232-1239

16. Murata S, Murata K, Kidena K et al (2004) A novel oxidative desulfurization system for diesel fuels with molecular oxygen in the presence of cobalt catalysts and aldehydes. Energy Fuels 18(1):116-121

17. Shiraishi Y, Hirai T (2004) Desulfurization of vacuum gas oil based on chemical oxidation followed by liquid-liquid extraction. Energy Fuels 18(1):37-40

18. Xiangfu Lin (2009) Modern spectrum analysis method. East China University of Science and Technology Press, Shanghai, pp 50-51 